\title{
The morphogenetic and regulatory functions of the Drosophila Abdominal-B gene are encoded in overlapping RNAs transcribed from separate promoters
}

\author{
Michael Zavortink and Shigeru Sakonju \\ Howard Hughes Medical Institute, Department of Human Genetics, University of Utah School of Medicine, Salt Lake City, \\ Utah 84132 USA
}

\begin{abstract}
The Abdominal-B $(A b d-B)$ gene of the Drosophila bithorax complex is a homeotic gene with two subfunctions: the morphogenetic element required for specifying the identity of parasegments (PS) 10-13 and the regulatory element that represses the expression of other homeotic genes in PS14. Here, we provide evidence that four classes of overlapping transcripts are generated from the $A b d-B$ gene and characterize three of the transcripts in detail. We determined the transcription initiation sites for the 4.6- and 3.4-kb RNAs and show that they are generated from separate promoters. Both of these transcripts are present throughout the period during which the $A b d-B$ subfunctions are required. A mutation that inactivates the morphogenetic function is associated with a 411-bp deletion of the initiation site for the 4.6-kb RNA. The regulatory function mutations disrupt the transcription unit for the 3.4-, but not the 4.6-kb, RNA. These results support the assignment of the morphogenetic function to the 4.6-kb RNA and the regulatory function to the 3.4-kb RNA. A 7.8-kb RNA expressed during embryogenesis may also contribute to the regulatory function. Sequence analysis of cDNAs indicates that the 4.6-kb RNA encodes a 55-kD protein (the $m$ protein), whereas the 3.4-kb RNA encodes a 30$\mathrm{kD}$ protein (the $\boldsymbol{r}$ protein). The $\boldsymbol{m}$ and $\boldsymbol{r}$ proteins share a carboxy-terminal sequence that includes the homeo domain, but the $r$ protein lacks a glutamine-rich amino-terminal domain found in the $m$ protein.
\end{abstract}

[Key Words: Homeotic; bithorax complex; Abdominal-B; multiple promoters]

Received July 10, 1989; revised version accepted September 18, 1989.

The identity of thoracic and abdominal segments in Drosophila melanogaster is determined by homeotic genes that are clustered in two regions of the genome: the Antennapedia complex and the bithorax complex (BX-C) (Akam 1987). The homeotic genes in the BX-C specify the identities of two thoracic and eight abdominal segments, corresponding to parasegments (PS) 5-14. Larvae deficient for the BX-C show the transformation of these segments to the posterior first thoracic and anterior second thoracic segment (or PS4) (Lewis 1978; for review, see Duncan 1987). Recent genetic analyses have revealed that the $\mathrm{BX}-\mathrm{C}$ contains three lethal complementation groups: Ultrabithorax $(U b x)$, abdominal- $A$ ( $a b d-A)$, and $A b d o m i n a l-B(A b d-B$ ) (Sánchez-Herrero et al. 1985a,b; Tiong et al. 1985; Casanova et al. 1987). The domains of activity for these homeotic genes can be inferred from the mutant larval phenotypes. The $U b x$ functions are primarily required for the identity of PS5 and PS6 and, to a lesser extent, PS7-PS13. The identity of PS7-PS13 is specified by the $a b d-A$ functions, and the $A b d-B$ functions are required in PS10-PS14. Hence, the domains of activity for these genes overlap, and the correct combination of encoded functions is required to specify unique segmental characteristics.
In addition to the lethal mutations, many $\mathrm{BX}-\mathrm{C}$ mutations have been isolated that are homozygous or hemizygous viable (Lewis 1978, 1985). These mutations transform only subsets of the parasegments affected by mutations in the three lethal complementation groups. The nonlethal mutations that affect the thoracic segments include $b x, a b x, b x d$, and $p b x$, whereas those transforming the abdominal segments are known as infra-abdominals (iab). The $i a b$ functions can be classified by complementation analysis into iab-2 through iab-8 (Karch et al. 1985; Lewis 1985; Duncan 1987). Cis/ trans complementation tests between many lethal and nonlethal mutations have indicated that the nonlethal functions require a wild-type copy of the lethal functions in cis (Lewis 1978, 1985). This has been interpreted to mean either that mutations in $U b x, a b d-A$, or $A b d-B$ cis-inactivate the neighboring nonlethal functions (Lewis 1979, 1985; Karch et al. 1985) or that the nonlethal functions represent cis-regulatory elements that control the expression of the three essential functions (Casanova et al. 1987; Peifer et al. 1987).

The BX-C has been cloned, and the locations of the three lethal complementation groups, as well as the nonlethal complementation groups, have been deter- 
mined by mapping associated DNA lesions (Bender et al. 1983; Karch et al. 1985). Low stringency hybridization experiments have detected homeo box sequences associated with the $U b x, a b d-A$, and $A b d-B$ regions (Regulski et al. 1985), suggesting that each gene encodes a homeo domain-containing DNA-binding protein(s). The $U b x$ domain has been characterized in greatest detail. All $U b x$ lethal mutations disrupt a $77-\mathrm{kb}$ transcription unit encoding the homeo domain-containing protein products expressed in PS5-PS13 (Akam 1983; White and Wilcox 1984; Akam and Martinez-Arias 1985; Beachy et al. 1985; Weinzierl et al. 1987; O'Connor et al. 1988; Kornfeld et al. 1989). The nonlethal mutations that affect thoracic segment identity map within the $U b x 5^{\prime}$-flanking region or within the $U b x$ introns (Bender et al. 1983). Furthermore, these nonlethal mutations alter the spatial distribution of the $U b x$ proteins, supporting the model that they alter cis-regulatory elements of $U b x$ (Beachy et al. 1985; White and Wilcox 1985).

Recent genetic analyses of $A b d-B$ suggest a complex gene organization within this lethal complementation group (Karch et al. 1985; Casanova et al. 1986; Sato and Denell 1986; Whittle et al. 1986; Celniker and Lewis 1987; Tiong et al. 1988). The current understanding of the genetic data can be summarized as follows: The $A b d-B$ gene contains two genetic elements or subfunctions. The morphogenetic, or $m$, element [revealed by the class I mutants described by Casanova et al. (1986)] is required for the development of PS10-PS13. The strongest mutant alleles affecting the $m$ function not only transform PS10-PS13 to PS9 but also cause near complete lethality during late embryogenesis. In addi- tion, nonlethal mutations such as iab-5, iab-6, and weak iab-7 alleles (Karch et al. 1985) transform subsets of the domain affected by lethal $m$ alleles, suggesting that they affect the expression of the $m$ function, by analogy to the $U b x$ domain. The mutations in the regulatory, or $r$, element [revealed by class II mutants of Casanova et al. (1986) and iab-8 mutants of Karch et al. (1985)] cause a transformation PS14 toward PS13; homozygous $r^{-}$flies are viable. Casanova et al. (1986) have presented evidence that the primary function of the $r$ element is to repress expression of other homeotic genes in PS14. Mutant alleles affecting only the $m$ element complement those affecting the $r$ element. However, both types of mutations fail to complement the strictly lethal class of $A b d-B$ mutations that affect PS10-PS14 [class III of Casanova et al. (1986) and strong iab-7 of Karch et al. (1985)]. This indicates that both the $m$ and $r$ elements are members of the $A b d-B$ lethal complementation group, and that class III mutations inactivate these subfunctions simultaneously.

To understand the complex genetic organization of $A b d-B$, we carried out a detailed molecular analysis. Current data indicate that four major overlapping transcripts are generated from the $A b d-B$ gene (Fig. 1 ; Kuziora and McGinnis 1988; Sánchez-Herrero and Crosby 1988). One of the transcripts has been localized by in situ hybridization analysis to PS10-PS13, whereas two other transcripts have been detected in PS14 and PS15 (DeLorenzi et al. 1988; Kuziora and McGinnis 1988; Sánchez-Herrero and Crosby 1988). These results suggest that the transcript expressed in PS10-PS13 carries the $m$ function, whereas one or both of the transcripts expressed in PS14-PS15 contains the $r$ function. How-

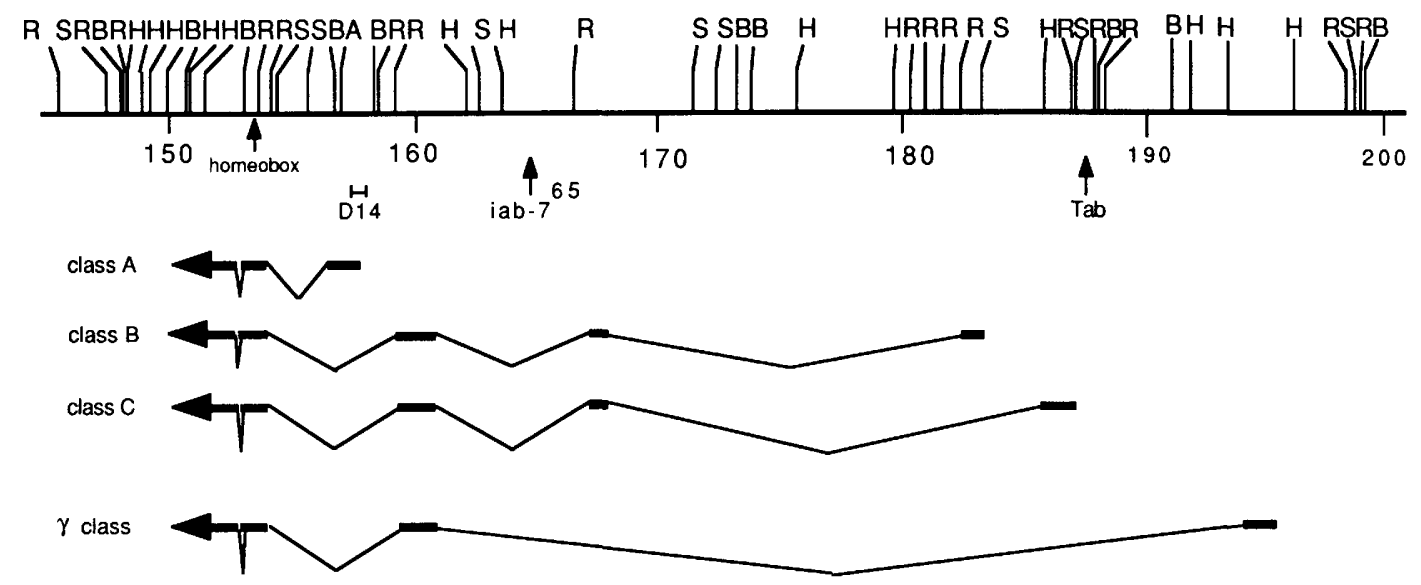

Figure 1. Localization of exons associated with three classes of $A b d-B$ cDNAs. The results of Southern analysis to localize genomic regions that hybridize to each class of $A b d-B$ cDNA are shown here with the genomic coordinates and restriction map of Karch et al. (1985). The numbers refer to the distance in kilobases from the chromosomal walk entry site. Bars indicate regions of hybridization with genomic restriction fragments but do not necessarily imply single exons. The direction of transcription, as indicated by arrows, is from right to left. We have also included the $\gamma$-class transcript described by Kuziora and McGinnis (1988) to provide a complete picture of transcript distribution in this region. Also shown is the location of the genomic region encoding the homeo box and the positions of the lesions associated with three $A b d-B$ mutations: $D 14$, a 411-bp deletion, and iab-765 and Tab, two chromosomal breakpoints. $D 14$ is a class I mutation $\left(m^{-} r^{+}\right)$, and Tab is a class II mutation $\left(m^{+} r^{-}\right)$. iab-765 has been classified as an 'atypical' class III $\left(m^{-} r^{-}\right)$mutation because embryos do not develop sclerotic plates in PS14; hence, iab-765 behaves as if the $m$ function is not completely inactivated. (A) $A v a \mathrm{I} ;$ (B) BamHI; (H) HindIII; (S) SalI (R) EcoRI. Not all AvaI sites are indicated. 
ever, it has not been demonstrated whether the $A b d-B$ transcripts are differentially spliced from a single precursor in different parasegments or whether they are transcribed from different promoters. Here, we report the isolation and detailed characterization of three classes of cDNA from the $A b d-B$ region. We show that the $A b d-B$ transcripts are initiated from at least three separate promoters. These results allow us to assign the $m$ and $r$ functions to specific $A b d-B$ transcripts on the basis of correlations with DNA lesions in the $m$ or $r \mathrm{mu}$ tant alleles. We also show that the transcripts share the identical exons, including the homeo box sequence, toward the $3^{\prime}$ end while possessing unique $5^{\prime}$ exons. The transcript carrying the $m$ function encodes a longer protein with a glutamine-rich amino-terminal domain, whereas the transcripts with the $r$ function encode a shorter protein without the amino-terminal domain. These results suggest a model of activation and repression by the two $A b d-B$ homeo domain-containing proteins.

\section{Results}

The structure of Abd-B cDNA clones reveals four classes of overlapping transcripts

Genomic DNA from the $A b d-B$ region has been cloned and characterized (Karch et al. 1985). To analyze transcripts encoded by the $A b d-B$ gene, we screened two cDNA libraries constructed from 3- to 12-hr (Poole et al. 1985) and from 8- to 12-hr embryonic RNA (Brown and Kafatos 1988). Restriction fragments located at map coordinate +154 and from +157 to +159 of the BX-C (Fig. 1; Karch et al. 1985) were used to screen the libraries (see Materials and methods). Additional cDNAs were ob- tained using subcloned DNA fragments from the original cDNA isolates. A total of 30 cDNA clones were isolated and analyzed by restriction enzyme mapping (Fig. 2). In some cases, similarities between cDNA clones were examined by single-strand hybrid analysis, as described by Bermingham and Scott (1988; data not shown). On the basis of these results, the cDNA clones were classified into three structurally distinct classes: A, $B$, and C (Fig. 2). The largest cDNAs from each class were radioactively labeled and hybridized to filters containing restriction fragments of overlapping genomic DNA from the right half of the $\mathrm{BX}-\mathrm{C}$ (map coordinate +15 to +200 of Karch et al. 1985). The results of the Southern analyses are diagrammed in Figure 1. All cDNA inserts hybridized to 5- and 0.6-kb EcoRI fragments located between map positions +148 and +154 . In addition, cDNA from each class hybridized to unique fragments mapping distal to the common fragments. Class A cDNAs (E32, B3, and 16 other clones) hybridized to the 1-kb BamHI fragment at +158 . Class B cDNAs (E19 and four other clones) hybridized to two EcoRIHindIII fragments $(+159$ to +162 and +167 to +176$)$ and to an EcoRI-SalI fragment $(+182$ to +183$)$. Class C cDNA (E61) hybridized to the same fragments as class $B$ cDNA, except for the fragment at +183 ; the class $\mathrm{C}$ probe also hybridized to a unique HindIII-EcoRI fragment between +186 and +187 . To summarize, each of the three classes of overlapping $A b d-B$ transcripts contains at least two common exons, including the homeo box sequence, but has unique $5^{\prime}$ exons. Figure 1 also shows the exon locations of the $\gamma$ class of cDNA isolated by Kuziora and McGinnis (1988). cDNAs corresponding to this class of $A b d-B$ transcript were not detected in our screens.

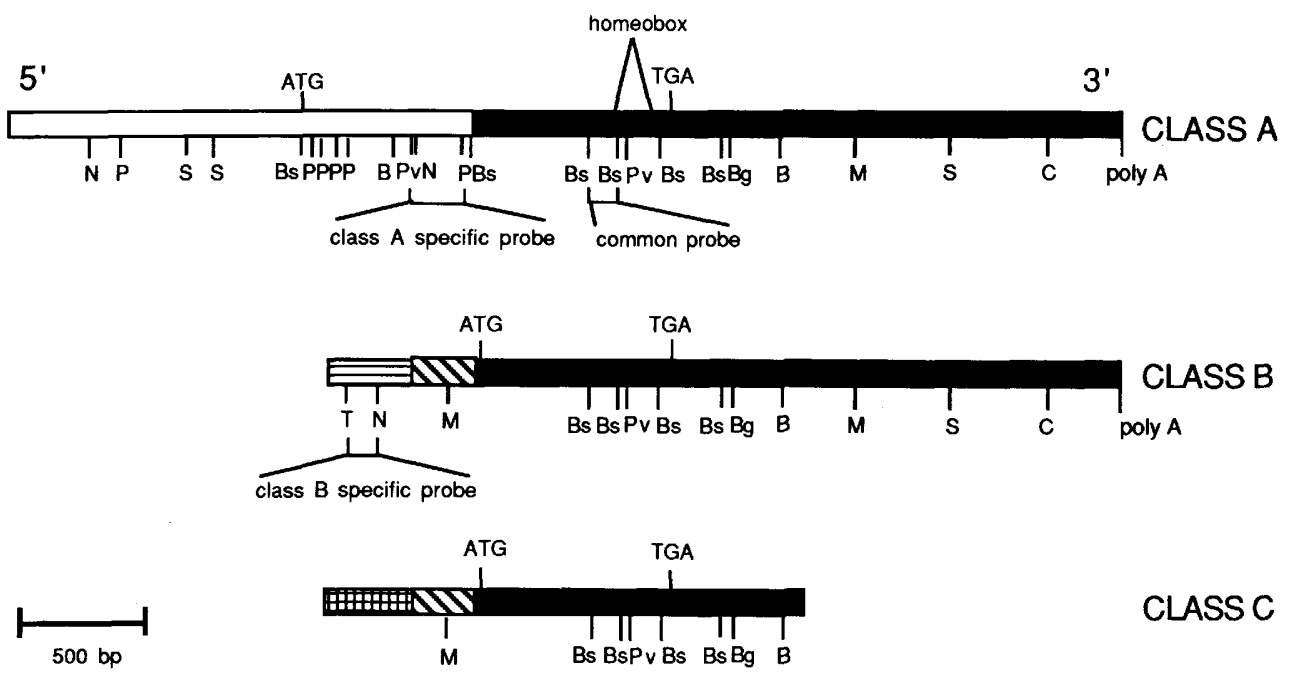

Figure 2. Restriction map and sequence relatedness of three classes of cDNAs. The region of identity between the three cDNA classes is shown by the solid black bar. Regions of additional identity between class B and class C cDNAs are indicated by the diagonally striped bar, whereas sequences unique to the three cDNA classes are represented by a clear bar for class A and horizontally striped or crosshatched bars for class B and class C cDNAs, respectively. The location of probes used in cDNA library screens and Northern analysis is indicated, as well as the positions encoding the homeo box, the proposed ATG initiation codons, and the TGA stop codon. Abbreviations are as in Fig. 1. Additional sites: (Bs) BstNI; (Bg) BglII; (C) ClaI; (M) MluI; (N) NaeI; (P) PstI; (Pv) PvuII, (S) SspI; (T) TaqI. For simplicity, not all TaqI sites are shown. 
To determine the size of the transcripts represented by the three classes of cDNA, we performed Northern blot analysis using probes specific to class $\mathrm{A}$, class $\mathrm{B}$, and a region common to all cDNA classes (see Materials and methods; Fig. 2). A class A-specific probe detects a major transcript of $4.6 \mathrm{~kb}$ and a minor transcript of $5.0 \mathrm{~kb}$ (Fig. 3 , lane C). A major transcript of $3.4 \mathrm{~kb}$ and a minor transcript of $3.8 \mathrm{~kb}$ are detected (Fig. 3, lane A) with a class B-specific probe. When a probe containing DNA sequences common to all three cDNA classes is used as a probe, both the major 3.4- and 4.6-kb RNAs and the associated minor transcripts are observed (Fig. 3, lane B). Kuziora and McGinnis (1988) have provided evidence that the minor species of RNA observed on the Northern blots are the products of alternative polyadenylation. We will henceforth refer to the $A b d-B$ transcripts by using the size of the major bands: $4.6-\mathrm{kb}$ class A RNA and 3.4$\mathrm{kb}$ class B RNAs. We have not detected additional bands with the common probe that may represent the class $C$ cDNA, nor have we been able to detect a band using a class C-specific probe. However, Sánchez-Herrero and Crosby (1988) detected a 7.8-kb RNA at low levels in 4to 8-hr embryonic poly $(\mathrm{A})^{+} \mathrm{RNA}$, using genomic DNA probes corresponding to our class $\mathrm{C}$-specific exon. This suggests that our class $\mathrm{C}$ cDNAs correspond to the 7.8-

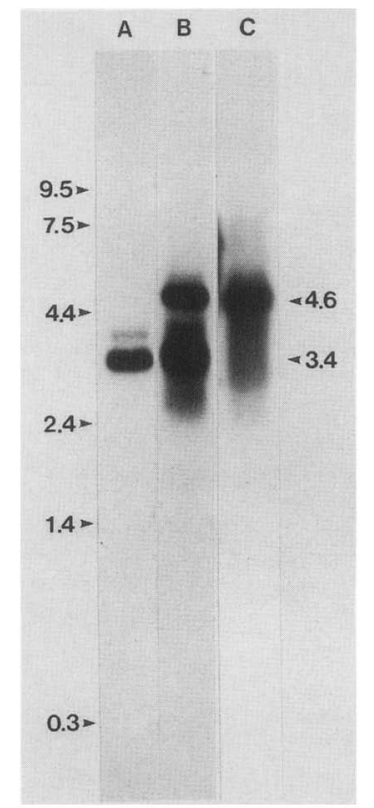

Figure 3. Northern analysis using cDNA class-specific hybridization probes. Ten micrograms of poly $(A)^{+}$RNA from 4- to 12-hr embryos was used per lane in this Northern analysis to correlate cDNA classes with their corresponding mRNAs. (Lane $C$ ) Hybridization of a single-stranded probe specific for class A cDNAs; (lane $A$ ) hybridization specific for class $B$ cDNAs; (lane $B$ ) hybridization using a single-stranded probe from a region of the cDNAs common to all three cDNA classes. Specific probes were a PvuII-PstI fragment for the class A cDNA; a TaqI-NaeI fragment for the class B cDNA; a BstNI fragment common to all three cDNA classes. The locations for these probes are shown in Fig. 2. The position of sized RNA standards (BRL) is shown by arrowheads at left. kb RNA. The direction of transcription for both the 4.6and 3.4-kb RNAs is from distal to proximal on the chromosome (right to left on the genomic map in Fig. 1) based on the single-stranded probes used for this analysis. Sánchez-Herrero and Crosby (1988) reported that the 7.8-kb RNA is transcribed in the same direction.

Kuziora and McGinnis (1988) have detected 3.3-kb and 3.7-kb RNAs using a probe specific to the $\gamma$-class cDNA. It is likely that transcripts corresponding to the class $B$ cDNAs and to the $\gamma$-class cDNAs would not be distinguishable as separate bands on Northern blots probed with common exon sequences (see Fig. 3, lane B). Taken together, these data indicate that four overlapping mRNA species are transcribed from the $A b d-B$ region.

\section{Determination of the transcription initiation sites for class $A$ and class $B$ RNAs}

To determine whether the $A b d-B$ RNAs are transcribed from the same or separate promoters, we localized the $5^{\prime}$ end of class A (4.6-kb) and class B (3.4-kb) RNAs by primer extension and S1 nuclease protection analyses (Figs. 4 and 5). The approximate position of the $4.6-\mathrm{kb}$ RNA initiation site was located with a primer complementary to a site 130 bp from the $5^{\prime}$ end of the B 3 cDNA. The primer extension product was $\sim 650$ nucleotides long (data not shown), indicating that the initiation site is located beyond the sequence contained in cDNA clone B3. Then we determined the genomic DNA sequence immediately upstream from the $5^{\prime}$ end of the $\mathrm{B} 3$ cDNA, synthesized a uniformly radiolabeled primer, and repeated the primer extension analysis (Fig. 4A,C). The size of the major extension product (Fig. 4A, lanes 2-4) indicates that the transcription start site is 506 bp upstream of the $5^{\prime}$ end of cDNA clone B3 (indicated as +1 in Fig. 4). This site of initiation was confirmed by two other primers complementary to the genomic sequences upstream of the B3 clone (data not shown).

S1 nuclease analysis supports this location for the 4.6$\mathrm{kb}$ RNA initiation site. A single-stranded genomic DNA probe, extending from $191 \mathrm{bp}$ downstream to a BamHI site upstream of the putative initiation site, protected RNA fragments of 189-191 nucleotides from S1 nuclease (Fig. 4B,C). Two other probes protected fragments consistent with the start site predicted from the primer extension experiments (data not shown). We chose the strongest band in our primer extension experiments as the start site, although minor initiation sites are indicated by the presence of faint bands at $+2,-1$, and -3 positions. We conclude that the transcription initiation site for $4.6-\mathrm{kb}$ class A RNA is located at the genomic map position +158 , a position within an intron of other $A b d-B$ transcripts.

Comparison of the size of the RNA predicted by Northern analysis and the sequence of class B cDNA clone E19 (see below) suggests that it is approximately full length. Therefore, we sequenced a region of genomic DNA upstream from the $5^{\prime}$ end of this cDNA clone to look for evidence of promoter elements or splice sites (Fig. 7). Although the cDNA contains 8 bases at the $5^{\prime}$ 


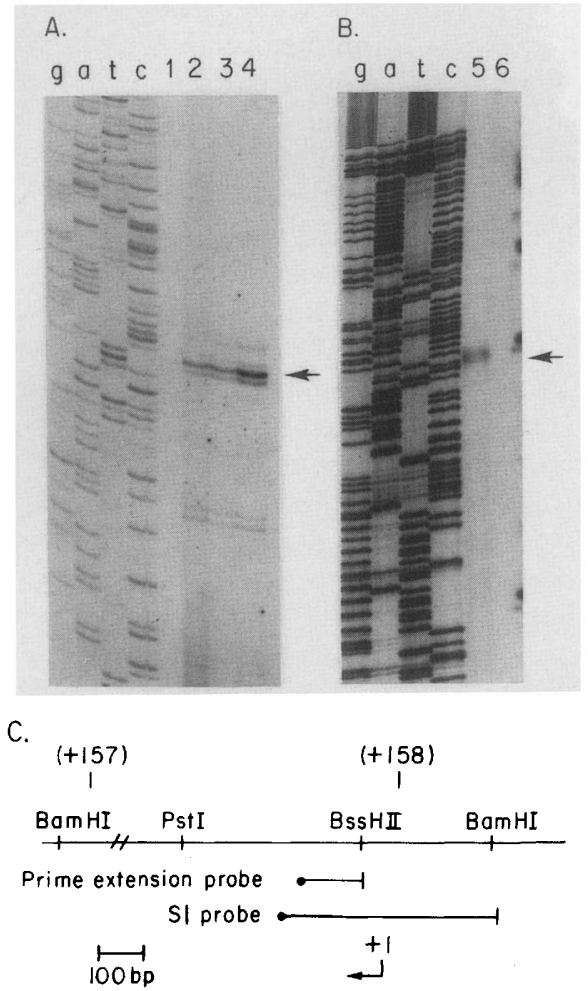

Figure 4. Primer extension and $\mathrm{S} 1$ nuclease analysis of the $5^{\prime}$ end of the 4.6-kb RNA. (A) Primary extension products obtained by hybridizing a uniformly radiolabled, 113-nucleotide primer complementary to nucleotides +39 to +151 (Fig. 6) to 1 $\mu \mathrm{g}$ of yeast poly(A) ${ }^{+}$RNA (lane 1), $10 \mu \mathrm{g}$ of Drosophila 4- to 12-hr embryonic total RNA (lanes 2 and 3), and $1 \mu \mathrm{g}$ of 4 - to 12-hr embryonic poly(A) ${ }^{+}$RNA (lane 4). (Lanes $g, a, t$, and $c$ ) Sequence ladders made with an oligonuceotide primer (nucleotides +125 to +151 ) were electrophoresed to determine the transcription initiation site. For S1 protection analysis $(B)$, a single-stranded probe was made by priming DNA synthesis with another primer (nucleotides +162 to +191 ) on a genomic subclone template to produce a uniformly labeled 536-nucleotide probe extending to the BamHI site (nucleotide -345 in Fig. 6). This was hybridized to either Drosophila 4- to 12-hr embryonic total RNA (lane 5) or yeast poly(A) ${ }^{+}$RNA (lane 6) and the S1-protected fragments electrophoresed next to the corresponding sequencing ladder (lanes $g, a, t$, and $c)$. (C) Schematic of the genomic locations of the primer extension and S1 probes, and the transcription initiation site.

end not present in the genomic sequence, the genomic sequence in this region bears little resemblance to a splice acceptor site. To determine whether these bases represent an upstream exon or are simply an artifact of cDNA production, $\mathrm{S} 1$ nuclease protection and primer extension analyses were performed.

S1 analysis was performed using a uniformly radiolabeled probe extending from nucleotide +294 of class $B$ cDNA to a genomic PstI site located upstream (Fig. 5B). Figure 5A shows that 291-292 nucleotide fragments are protected from S1 nuclease digestion by RNA. Three other probes gave the same result (data not shown) and did not reveal any additional exons in the region $2.8 \mathrm{~kb}$ upstream of the $5^{\prime}$ end of class B cDNA.
Results of primer extension analysis also indicate that this position is the transcription initiation site rather than an intron/exon boundary. Extension of a uniformly labeled primer resulted in a band (Fig. 5) that places the initiation site for $3.4-\mathrm{kb}$ class B RNA at nucleotide +1 (Fig. 7A). These results indicate that the class B E19

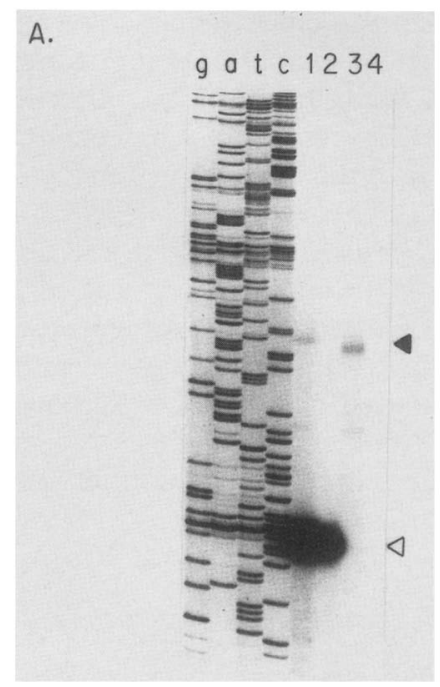

B.

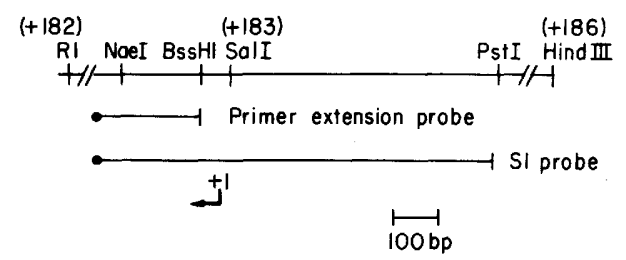

Figure 5. Primer extension and $\mathrm{Sl}$ analysis of the $5^{\prime}$ end of the 3.4-kb RNA. A primer from the $5^{\prime}$-end sequence of class B cDNA (nucleotides +275 to +294 ; Fig. 7 ) was extended in the presence of radioactive deoxynucleotides by the large fragment of DNA polymerase I to the BssHII site at +41 (B and Fig. 7). The uniformly labeled primer was then hybridized to either 10 $\mu \mathrm{g}$ of 4- to 12-hr Drosophila total RNA $(A$, lane 1) or $1 \mu \mathrm{g}$ of poly $(\mathrm{A})^{+}$yeast RNA (lane 2$)$, and the duplex extended with reverse transcriptase. This results in a 294-nucleotide extended product (solid arrowhead) that corresponds to a $\mathrm{C}$ residue (indicated as +1 in Fig. 7A). The genomic sequence in adjacent lanes $(g, a, t, c)$ was produced using the same primer at nucleotides +275 to +294 . For S1 nuclease analysis, the same primer was extended to a PstI site $\sim 900$ bases upstream from the putative transcription initiation site on a single-stranded genomic template (Materials and methods). After hybridization to either Drosophila 4- to 12-hr total RNA (lane 3) or yeast poly(A)+ RNA (lane 4), the reactions were digested with S1 nuclease and the protected fragments were electrophoresed on a $6 \%$ acrylamide/7 $\mathrm{M}$ urea gel. The protected fragments /solid arrowhead in A) are 1-3 bases shorter than predicted from the primer extension analysis, presumably because of the nibbling of the ATrich sequence at the $5^{\prime}$ end by $S 1$ nuclease. The open arrowhead $(A)$ indicates the unextended primer extension probe $(B)$ used in the primer extension reaction. The hooked arrow in $B$ shows the initiation site and the direction of transcription for the class $B$ transcript. The numbers in parentheses refer to genomic map positions (Karch et al. 1985) 
cDNA is 2 bp short of full length and, therefore, that the additional 8 bases on the $5^{\prime}$ end are apparently an artifact of the original cDNA cloning. The site of initiation for class B RNA (map position +183 ) is downstream from the 5 '-most exons of the 7.8-kb class C RNA and the $\gamma$ transcript and upstream from the class A transcription initiation site. We conclude that there are a minimum of three promoters in the $A b d-B$ gene.

We examined the DNA sequences around the initiation sites of class A and B RNAs for conserved transcriptional signals. The sequence at the initiation site of class A RNA, AGTGTA, is in close agreement with the cap sequences of a number of other Drosophila genes (Pirrota et al. 1987). The sequence AGTGTA also appears at a position $24 \mathrm{bp}$ downstream from the initiation site of class B RNA. Neither initiation site is preceded by a consensus TATA sequence. A notable sequence located 183-131 bp upstream of the class A transcription start site is a 53-bp stretch of poly[d(C-A)]/poly[d(G-T)]. Long stretches of CA/GT repeat have been observed in mouse and Drosophila genomes, but their functions remain unclear (Bhandari et al. 1988).

\section{An m element mutation deletes the transcription initiation site for the class $A$ RNA}

A class I mutation, D14, which inactivates the morphogenetic but not the regulatory function, has been shown to carry a deletion of $\sim 400 \mathrm{bp}$ that maps near the genomic map position +158 (Karch et al. 1985), close to the 5' end of the class A RNA. The precise deletion end points were determined by comparing the sequence of subcloned D14 genomic DNA with that of wild-type DNA. D14 is associated with a 411-bp deletion extending from $66 \mathrm{bp}$ upstream to $345 \mathrm{bp}$ downstream of the transcription initiation site for the class A RNA /Fig. 6). This deletion falls within a $5-\mathrm{kb}$ intron of class $B$, class $\mathrm{C}$, and $\gamma$-class RNAs (Fig. 1) and is unlikely to significantly affect the expression of these RNAs. The fact that the D14 mutation specifically deletes the transcription initiation site for the class A RNA provides evidence that this RNA encodes the $m$ function affected in the class I mutations of Casanova et al. (1986).

Two different proteins are encoded by the three classes of cDNAs

Because genetic analysis indicates that the $m$ and $r$ elements of $A b d-B$ carry out distinct functions, we wished to determine whether the three classes of RNA encode different protein products. The complete sequences of the longest cDNA inserts representing 4.6-kb (class A), 3.4-kb (class $B$ ), and 7.8-kb (class $\mathrm{C}$ ) RNAs were determined. Figures 6 and 7A show composite DNA sequences for class $\mathrm{A}$ and class $\mathrm{B} \mathrm{cDNAs}$ and their respective upstream genomic DNAs, whereas Figure $7 \mathrm{~B}$ indicates the sequences of exons specific to class $\mathrm{C}$ cDNA. The location of the exon/intron boundaries for the 45-bp exon of class B and C RNAs was also confirmed by sequencing the appropriate genomic DNA. The DNA quences confirm the exon structures predicted from the Southern analysis of the three cDNA classes: All three classes share the 3' exons; class $B$ and $C$ transcripts share two additional internal exons; and each class is associated with a unique $5^{\prime}$ exon. Both cDNA clones E32 (class A) and E19 (class B) have poly(A) tails at their 3' ends preceded by a canonical AATAAA polyadenylation signal (Fig. 4). The cDNA clone E61 (class C) does not contain a poly(A) tail at its $3^{\prime}$ end and appears to be a truncated cDNA.

Each class of cDNA contains a single long open reading frame (ORF). The ORF in the class A cDNA starts in the unique $5^{\prime}$ exon at +1211 (Fig. 6) and continues for $1478 \mathrm{bp}$ into the common $3^{\prime}$ exons. Conceptual translation of this ORF indicates that the class $A$ cDNA encodes a protein of 493 amino acids ( $55 \mathrm{kD}$ ). The ORFs present in class B and C cDNAs are contained entirely within the $3^{\prime}$ exons that are common to all three classes of cDNA. If translation initiates from the AUG at position +1880 (Fig. 6), the protein encoded by class B and $\mathrm{C}$ cDNAs will be a shorter protein of 270 amino acids $(30 \mathrm{kD})$. Thus, class $B$ and class C RNAs encode a protein that is a truncated form of the protein produced by class A RNA. These results are summarized in Figure 8.

\section{Discussion}

Four overlapping Abd-B transcripts are generated from multiple promoters

Genomic DNA from the $A b d-B$ gene detects four major classes of overlapping transcripts on Northern blots (Fig. 3; Kuziora and McGinnis 1988; Sánchez-Herrero and Crosby 1988). Each class (probably including the 7.8-kb RNA) is associated with less abundant transcripts that are longer by 400 nucleotides and appear to represent alternative polyadenylation products. Three of the major transcripts, 4.6, 3.4, and 7.8, are represented in the cDNA clones obtained and define three structurally distinct classes: $A, B$, and $C$, respectively. A fourth class of cDNA, $\gamma$, representing 3.3- and 3.7-kb RNA, has been isolated by Kuziora and McGinnis (1988). The $\gamma$-transcript sizes are similar to the sizes of transcripts detected by our class B-specific probes; however, the 3.4$\mathrm{kb}$ class B RNA initiates at a position $\sim 12 \mathrm{~kb}$ downstream of the $5^{\prime}$-most exon for the $\gamma$-class transcripts (Fig. 1). Class A most likely corresponds to the previously described $\alpha$-class cDNA (Kuziora and McGinnis 1988). Class C cDNA corresponds to the cDNA described by DeLorenzi et al. (1988). Kuziora and McGinnis described another cDNA class, $\beta$. The 5 ' exon of this cDNA maps to genomic position +167 , the location of the second exon present in our class B and C cDNAs, and contains additional sequences from this region. Therefore, this class may represent an incomplete cDNA produced from a precursor for the $3.4-\mathrm{kb}$ class B or 7.8 -kb class $\mathrm{C}$ transcripts.

We have shown by DNA sequence analyses that the $A b d-B$ transcripts represented by class $\mathrm{A}, \mathrm{B}$, and $\mathrm{C}$ cDNAs share exons spanning $2.5 \mathrm{~kb}$ of $3^{\prime}$ sequences but 
AGCCGCACCAACTGCCATCAACATAACATCAACCACCACCACCATCAATCTGAGTGCTTGTGCAACATGCGCATGTCCGCCCTCTCTTCCAAGTCACACG -194 GACGGGGAGGCACACACACACACACACACACACACACACACACACACACACACACACACACACTGGAGCGGGCTGGCGCCGCTGCCGTTAGAGTTTGTGT -94

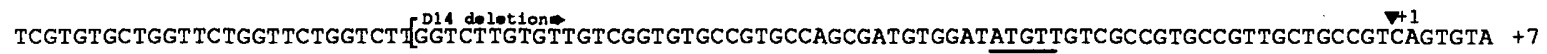
GATTTGTGCTTCGCTCTGTTCGGTTGGAAGECGCGCGGGCGTCCAGCAGCAACAACAGCAACTACAACAACAGCCGAGGCAAGCGGCCCTGCAACTTCGT +107 CGAGGACTGGGACTTGAACGATTTCGTACTCGCCGTCCATTCACATTCACATTCGACTGGGAGTGTTTCGTTCGAACGGTTCGAAAAATACAAGTTGAAC +207 ATTTTCGAAAAATTTAACTGAAAGAAGAAACGTTTTTGGAGTCGTATAAAAAATTAAATCAAAAAACAAAAAACACAATCAAAACATCGTGTCGCCGGCG +307 TTGTGAGGAGAAATAATAGCATTTTTGTTAACTGTTG dAAACATTGCCTTTAATTGTTTGTTTTGGTCGTAAAATCAAATTTTATGACCAGCAACATAAA +407 AAGCGAACGCCAGCAGCAGCAGCAACAACAACTGCAGGCCCCACAAATAATAAACTATTTATGATAATTATAAAAGAGAGAAGAAAATCAAAAACAAACG +507 - B3 CDNA

CCAACCGAAAAAAAAGAAAAGTGAAAAGAAAACATTAACTGACAAAGGGAAAATTGGAAAAGTTTTGGAAAATTGGATTGACCGAATGAAAACTGAAAAA +607 AGCCAATTTGAAAATACTGCGTGAGTTGCTGACGACCGCAAACACCCTGTGAAATCCAAGCTGATTCGATCCCCTGTGCAACAACAAAGTGACTCTCTTC +707 GCCCGCTCTTTAGGCAGTGTGCGTGTGTGAGTAAGTCGGCGTGTGCGTGTGACCGCTGACGGACGTTTGTGTGCGTGTGCGGTACGCAAATAAAAGGGC +807 AGAACTCGAGTAAAGGTGCTCTGAATATTAAAAATAAAAATTATTTAGTCGCGAAAAAATAAAAAGAGACTTAAACAATTAGAAAGGCGTCACTCAGAG +907 GAGTGAGAAAAAAAAGACAGAGAAAGGTCGGTGGGTCGAGGCGATCGACCCCACTGCACCGCCTTTATCCTCGCCGCCGCAGTTCGAGTGCAACGCGTCC +1007 AAGATAACCGTAAATATTCCACCCCTCCCCCAAACCCCAACCATCCCGCTGGGTGCGCTCTCTACGACCCCCACGATGTCTCGGCAGTCGGGTCGCACGC +1107 CGCTGCCGGGGCGTGGTGGGGGCATCATACACACACCCACACCCACGTACCCACCGCCCCGCACCCGCATCCGCATCCCCAGGCGCATCCCTCCCTGCCC +1207

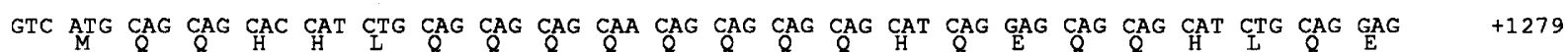
CAG CAG CAG CAT CTG CAG CAA CTG CAT CAC CAT GCG CAC CAC CAC CTG CPCT CAG CCT CTC CAC ACC ACC AGC

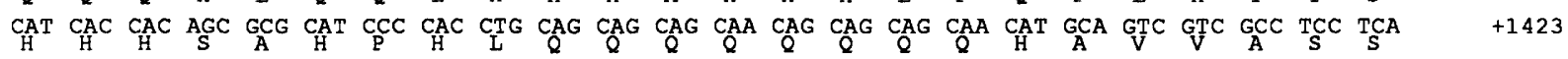

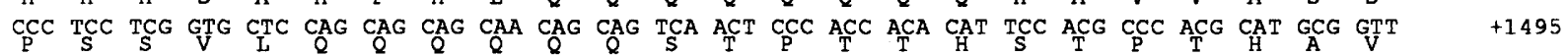

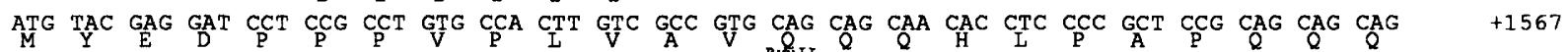
CAG CAA CTC CAA CAG CAG CAG CAA CAG CAG CAA CAA CAG CTG GCG ACA ACA CCG GTG GCC GGC GCC CTC AGT CCC GCC CAA ACA CCC ACT GGA CCT TCC GCC CAA CAA CAG CAA CAT CTC ACA TCG CCC CAC CAC CAG CAA CTG

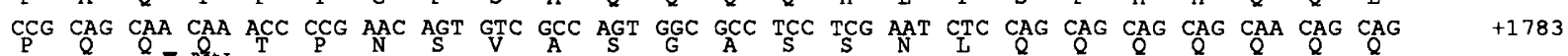
AAT GCT GCA GTT GCT CCT GGC CAG ACG CAG ATC GTT GCG CCG ACC ACG GCG AGT GTT TCT CCC TCC AGT GTT AGT TCT CAG AAG GAA Gomb ATC AAT ${ }_{S}$ ATG TCC ATC CAA TTA GCG CCA CTG CAT ATA CCC GCC ATC CGG GCC GGT

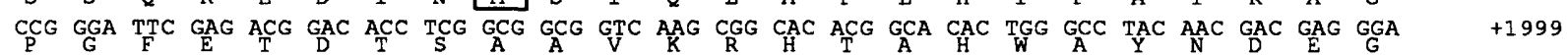

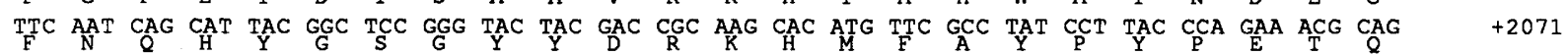

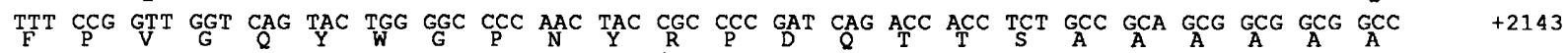
TAC ATG AAC GAG GCG GAG CGC CAC GTG AGC GCC GCC GCG CGA CAG TCC GTC GAG GGC ACA TCG ACG TCC AGC TAC GAG CCG CCC ACC TAC TCC TCG CCA GGC GGC CTG CGC GGC TAT CCC AGC GAG AAC TAC TCC AGC TCA GGA

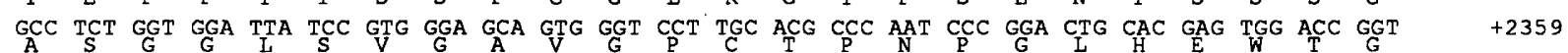

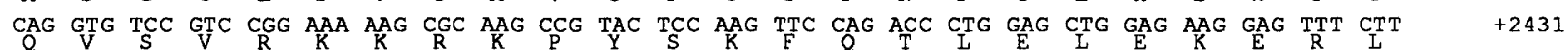

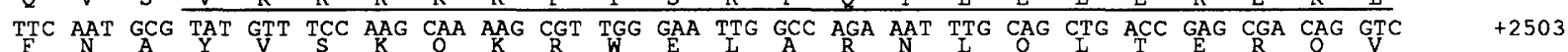

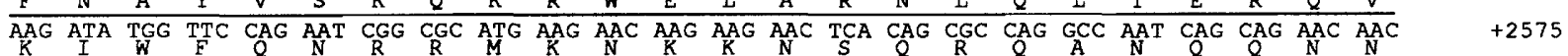

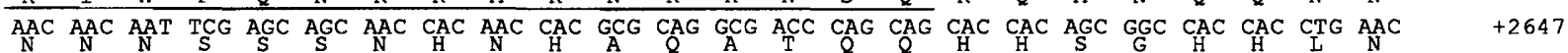

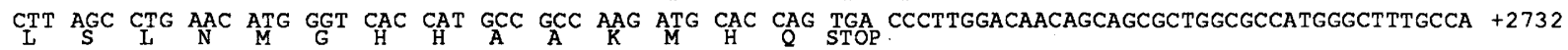
CCTACTAGCAGTTAGCCAATCCGAGTTCGGGTAACCCCAGCTCGAATCCCAACCCCATGTCCGATCCGAATCACCATCATCTAATCAAGAACGAGCTGGC +2832 CATGGACTTTCCATGCTAGTCCAGCGATTGGAAGGGCGATTCCAGCCAGGCCGAGTTCAGTCGGTTAAATGTACAAAAACCAGAGATCTCTAGCATGCGG +2932 GATAGGAATATGTGACCACAATGAGGAGCAAGGATGTGGATGAGCAACTGCCCAGAAGTGCGCAGGCGTCGCTGATGTGTGACCAACCGACGTTGATGGA +3032 AATGCAGTTTATTATTAAGTCAGTTCTACGGATCCCAGAGATCCAAGCCCCAACACGATAATGCAGCTTAGTTCGGTAGTTGAATATAGATACGAGTAAG +3132 ATGAAGAGTAAGCAGCAGCAGTAGCAGATGCACTTGAAATTCGCAACTGTACGAAAATATATGTATGTACGTATTTCTCTCAACGCTCTCATTAGCCTAG +3232 GCGAGCACTATGAATTTTCCGAACTATAAATTATGAATATGAATATACTTAAACGTCAGTGAATATAACCCCGCATAAATTATGAATACACGCGTTCGAG +3332 TCGATAGATTTTACCATACCTATXCAATTAAGAGCGGCCACAAGGGGCT GAGTTAGGCTGAGCAGCAGAACACATTTTAGACCCAGATAAATGTTCTTGAA +3432 TAGTAGATTT TACCATACCTATXCAATTAAGAGCGGCCACAAGGGGCTGAGTTAGGCTGAGCAGCAGAACACATTTTAGACCCAGATAAATGTTCTTGAA + +3432
ACACAAATTGAAATTGTTTAACAATTTTCGGACCCTCACAGCTCCGCAAACAAGAAGACACACTCCGCAGTCTAGGATAAATTTGTCGTATAATGTTC +3532 GTCGTGTCGTGTCCTTTGATACCTTCTAAGTTCCTGTATATAAACTAAGACATTGCGCTGATTTCCGGCCGAAGCGAGCACTCGATAACTAAATTACATC +3632 AGATATATGTATATGTATATTGCGTACACGAGAGATATTCAATATTTGTATAATATGAACTCGGATTCGATTTTAGCAAATGGTTAATTGTAAGTTGCAA +3732 AAATTTCAATGAGTGTGTGCATGTTTACCCCATAGTTGAAGTCGCTTTCGAATTAAATTAACTCTTAAACCAAGGAAAACACTTAACAAAACTACTCGTA +3832 AAGCTAAAGCAACAAAAACTTAAAAGATACACACTTAACAGAAGTAAGCGAGTGTGAAAACGATGGAGGGGAGATGTCGGGGAGGAGTAATTAGCATACC +3932 GTAACAGCTACTTATATAACATACACATAGTACATATAGTAATCGTACATATGCATACATATATTTTCATGTGTATCGACGCCGCTTGATCCTGATATTA +4032 AGTCTAAGTTTAGTTGTGTTGTGTAATTATCGATTTTGTTAATGTTTTGCCCCGAGCATTATATTATATTATGCTAACCTATACCTATACCTATACCTAC +4132

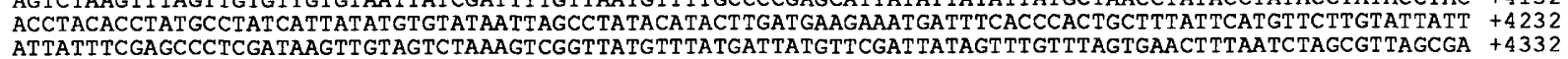

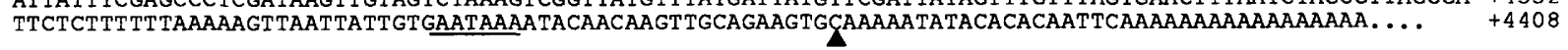

Figure 6. (See following page for legend.) 
have unique $5^{\prime}$ exons. Two lines of evidence indicate that the 7.8-kb RNA is not a precursor of the 3.4-kb RNA: DNA sequence analysis shows that the $5^{\prime}$ exon of the 3.4-kb RNA is not present in 7.8-kb RNA, and the 3.4-kb RNA initiation site is located downstream of the 7.8-kb RNA 5' exon. Although the sequence of the $\gamma$ cDNA has not been reported, Southern analysis (Kuziora and McGinnis 1988) suggests that it too shares the same $3^{\prime}$ exons but possesses a unique $5^{\prime}$ exon (Fig. 1).

Our study shows that the $4.6-\mathrm{kb}$ class A transcript and $3.6-\mathrm{kb}$ class B transcript are generated from separate promoters. The class $\mathrm{A}$ and class $\mathrm{B}$ initiation sites are located downstream of the $5^{\prime}$ exons for both the $7.8-\mathrm{kb}$ transcript and the $\gamma$ transcripts, indicating the existence of at least one other promoter for the $A b d-B$ gene. The 7.8-kb RNA and the $\gamma$ transcripts show different patterns of expression (DeLorenzi et al. 1988; Kuziora and McGinnis 1988; Sánchez-Herrero and Crosby 1988), and their $5^{\prime}$ exons map to different positions. Thus, it is possible that these transcripts are differentially regulated at the transcriptional level and initiate from different promoters. Therefore, $A b d-B$ encodes primary transcripts generated from at least three and, perhaps, four different promoters.

A number of developmentally regulated genes in Drosophila and other organisms have been shown to produce overlapping transcripts from alternative promoters (for review, see Schibler and Sierra 1987). Notable examples in Drosophila are the $A D H$ (Benyajati et al. 1983), Antennapedia (Laughon et al. 1986; Schneuwly et al. 1986; Stroeher et al. 1986), and caudal (Mlodzik and Gehring 1987) genes. These genes contain alternative promoters that are regulated differentially during development. Because ORFs are found in the common exons of each of these genes, alternative transcripts encode the same proteins. The transcripts for $A b d-B$ differ in that two different proteins are produced (see below).

\section{Correlation of different classes of transcripts with Abd- B subfunctions}

Genetic analyses have identified two separate functions within the $A b d-B$ complementation group, termed the morphogenetic $(m)$ and regulatory $(r)$ elements. These subfunctions are revealed by class I $\left(\mathrm{m}^{-} r^{+}\right)$and class II $\left(m^{+} r^{-}\right)$mutants of Casanova et al. (1986). Three lines of evidence indicate that the $4.6-\mathrm{kb}$ class A RNA encodes the $m$ function affected in class I mutations of $A b d-B$. First, probes specific for the class A RNA detect expression in PS10-PS13, the region affected by class I mutations (Kuziora and McGinnis 1988; Sánchez-Herrero and Crosby 1988). Second, we have shown that a class I mutation, D14, which causes nearly complete lethality, is associated with a 411-bp deletion that removes the transcription initiation site for class A RNA. The deletion falls within a large intron for class $B$ and class C RNAs and, hence, is not expected to severely affect expression of these RNAs. Flies trans-heterozygous for $D 14\left(\mathrm{~m}^{-} \mathrm{r}^{+}\right)$ and $i a b-8\left(\mathrm{~m}^{+} \mathrm{r}^{-}\right)$show only a mild mutant phenotype /a rotation of male genitalial, indicating that the $r$ function of the D14 chromosome is not significantly affected (Celniker and Lewis 1987). Third, none of the break points associated with the $r^{-}$mutations disrupt the class A transcription unit (Fig. 1; Karch et al. 1985; Celniker and Lewis 1987). One breakpoint mutation, $i a b-7^{65}$, that weakly affects the $m$ function is located 8 $\mathrm{kb}$ upstream of the promoter for class A RNA. This location is closer to the promoter than any of the $r^{-}$mutant break points.

The $r$ function of $A b d-B$ appears to be encoded by class $\mathrm{B}(3.4 \mathrm{~kb})$ RNA and possibly by class $\mathrm{C}(7.8 \mathrm{~kb})$ RNA for the following reasons. First, in situ hybridization with probes specific to these RNAs has detected expression in PS14, the parasegment affected by class II $\left(\mathrm{m}^{+} \mathrm{r}^{-}\right)$mutations (DeLorenzi et al. 1988; Kuziora and McGinnis 1988; Sánchez-Herrero and Crosby 1988). Furthermore, the breakpoints associated with these mutations either disrupt or are located close to the transcription unit for the 3.4- and 7.8-kb RNAs. DeLorenzi et al. (1988) have argued that the 7.8-kb RNA represents the $r$ subfunction of $A b d-B$. However, the time of expression of the 3.4and $7.8-\mathrm{kb}$ RNAs suggests that the $3.4-\mathrm{kb}$ RNA is likely to provide the $r$ function necessary for the development of adult terminalia. The time during which the $r$ function is required has been studied by A. Busturia and G. Morata (pers. comm.) using genetic mosaic analysis. $r^{-}$ clones induced as late as the third larval instar stage exhibit mutant phenotypes, indicating that the $r$ function is required at or after that stage. Northern blot analyses have shown that the $3.4-\mathrm{kb}$ RNA is present throughout development, whereas the 7.8 -kb RNA is detected only during 4-8 hr of embryogenesis (Kuziora and McGinnis 1988; Sánchez-Herrero and Crosby 1988). Therefore, these results suggest that the $3.4-\mathrm{kb}$ class B RNA is essential for the $r$ function.

Figure 6. Nucleotide sequence of class A cDNA and upstream genomic DNA and the predicted amino acid sequence of the ORF. Shown here are a composite sequence derived from two cDNAs E32 and B3 and sequencing of genomic subclones from wild type and $D 14$ between the PstI and BamHI sites at positions +158 and +159 . Sequences derived from cDNA clone B3 extend from nucleotides 508 to 1553 , whereas sequences from 1553 to the $3^{\prime}$ end were derived from another cDNA (E32). Positive numbers indicate nucleotides downstream from the putative initiation site, whereas negative numbers are upstream of the initiation site. Brackets delimit the sequence deleted in the D14 mutation (between -66 and +345 ). The homeo box region is underlined. The conceptual ORF for the cDNA is shown beginning with an ATG at +1211 and extends to a TGA stop codon at +2692 . The proposed translation initiation site in class B and class C cDNAs is boxed $(+1880)$. The arrow at nucleotide +1870 marks the end of the class A-specific exons and the beginning of the common exons. A weak homology to TATA box (nucleotide -27 to -23 ) and a putative poly(A) addition signal (nucleotides +4362 to +4367 ) are underlined. The arrow at +4389 shows the site of poly(A) addition for the class B cDNA clone E19. The primers used for primer extension (nucleotides +125 to +151 ), and nuclease $S 1$ protection $(+162$ to +191$)$ are also underlined. The PvuII and PstI sites that delimit the class A-specific probe used in the Northern analysis are marked, as are the BssHII and BamHI sites used in the primer extension and S1 nuclease protection analysis. Not all PstI, PvuII, BamHI, or BssHII sites are indicated. 
A)

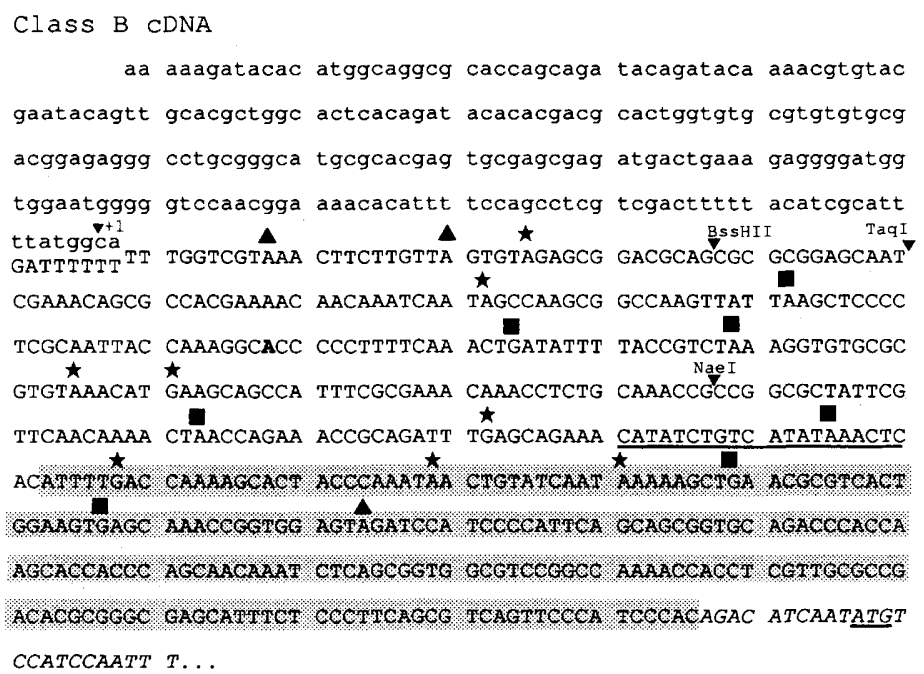

B)

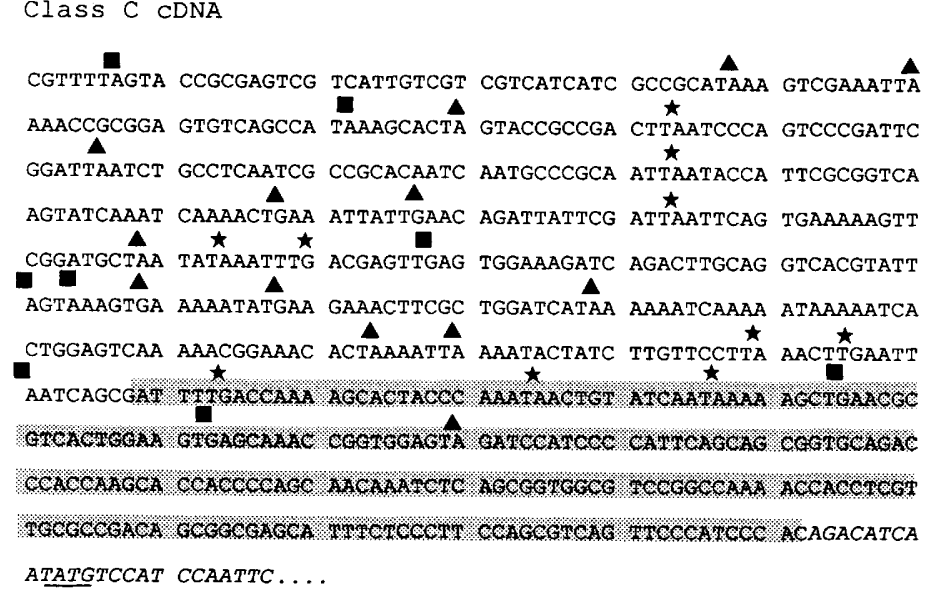

Figure 7. Nucleotide sequences of class B- and class $\mathrm{C}$-specific exons and the genomic DNA upstream of class B cDNA. Nucleotide sequences for the $5^{\prime}$ exons specific to class $\mathrm{B}$ cDNA clone E19 (A, unshaded uppercase letters) and class $C$ cDNA clone E61 ( $B$, unshaded uppercase letters) are shown here joined to the 223-bp exons (shaded uppercase letters) common to both classes. The $5^{\prime}$ exon specific to the class B cDNA has $302 \mathrm{bp}$. All but the first $8 \mathrm{bp}$ originate from a single exon located at position +184 on the genomic map. The sequence of the upstream genomic region is shown in lowercase letters. The class B cDNA sequence is numbered starting at the transcription initiation site $(+1)$ determined by $\mathrm{S} 1$ nuclease protection and primer extension analysis, whereas negative numbers are upstream from this site. Included in the class B sequence is the BssHII restriction site used in the primer extension analysis and the TaqI and NaeI sites used to make probes for Northern analysis. For simplicity, not all BssHII, TaqI, and NaeI sites are shown. The boldface $A$ at position +132 is the residue found in the cDNA sequence but not in the corresponding genomic sequence. The primer (nucleotides +275 to +294 ) used to synthesize the production for the S1 nuclease protection and primer extension analysis is underlined. The $5^{\prime}$-specific sequence shown for class C cDNA is identical with the sequence studied by DeLorenzi et al. (1988), with the exception that the sequence shown here has an additional $G$ residue located 182 bases from the beginning of the sequence. We have included, in italicized letters, the beginning of the next exon, common to all cDNA classes studied. The proposed translation initiation site for the $r$ protein encoded by both class B and class C cDNAs is underlined. $\star, \boldsymbol{\Delta}$, or $\boldsymbol{\square}$ stop codons in each of three frames shows that long ORFs are not present in exons specific to class $B$ and class $C$ cDNAs.
The genetic complexity observed by Celniker and Lewis (1987) in a screen for revertants of $T a b$ mutation may be relevant in assigning the $r$ function. Tab (a class II $\mathrm{m}^{+} \mathrm{r}^{-}$mutation) is associated with an inversion break point at map position +187 , located $\sim 4 \mathrm{~kb}$ upstream of the class B RNA promoter and within the transcription unit(s) for class $\mathrm{C}$ and $\gamma$ RNAs. They recovered several revertants of $T a b$ that resulted in a more extreme loss of the $r$ function. These revertants are associated with new breakpoints downstream of the promoter that would completely disrupt the class B transcript. These results suggest that the $T a b$ breakpoint affects regulation of class B RNA and that the disruption of the class B transcript in the $T a b$ revertants leads to a complete loss of the $r$ function. The $7.8-\mathrm{kb}$ class $\mathrm{C}$ transcript may provide additional $r$ functions during early embryogenesis.

Functions of the $\gamma$-class transcripts are unclear at present. These transcripts are localized to PS15 where defects have not been observed in most $A b d-B$ mutants. Possible roles of the $\gamma$ transcripts have been discussed by Kuziora and McGinnis (1988).

\section{Abd-B encodes two proteins with different functions}

The conceptual translation of the long ORF associated with class A RNA predicts a protein of $55 \mathrm{kD}$. Because this transcript has been correlated with the $m$ subfunction of $A b d-B$, the encoded ' $m$ protein' is required for the specification of the identity of PS10-PS13. Both class B and class $C$ RNAs are associated with an ORF that could encode a protein of $30 \mathrm{kD}$, the ' $r$ protein'. If translation begins at the AUG at nucleotide +180 (Fig. 4), the $r$ protein would simply be a truncated form of the longer $m$ protein. DeLorenzi et al. (1988) proposed that the ORF in the 7.8-kb RNA may begin with a GUG codon located $87 \mathrm{bp}$ upstream of the AUG because of the presence of opa repeat in this region. In eukaryotic systems, GUG is a poor initiator for both in vivo and in vitro translation (Peabody 1989; R. Eisenman, pers. comm.). Because some opa repeats are located outside of ORFs (e.g., see Bossy et al. 1988), their presence is not necessarily an indicator of translated sequences. Therefore, we consider it more likely that initiation occurs from the AUG. 


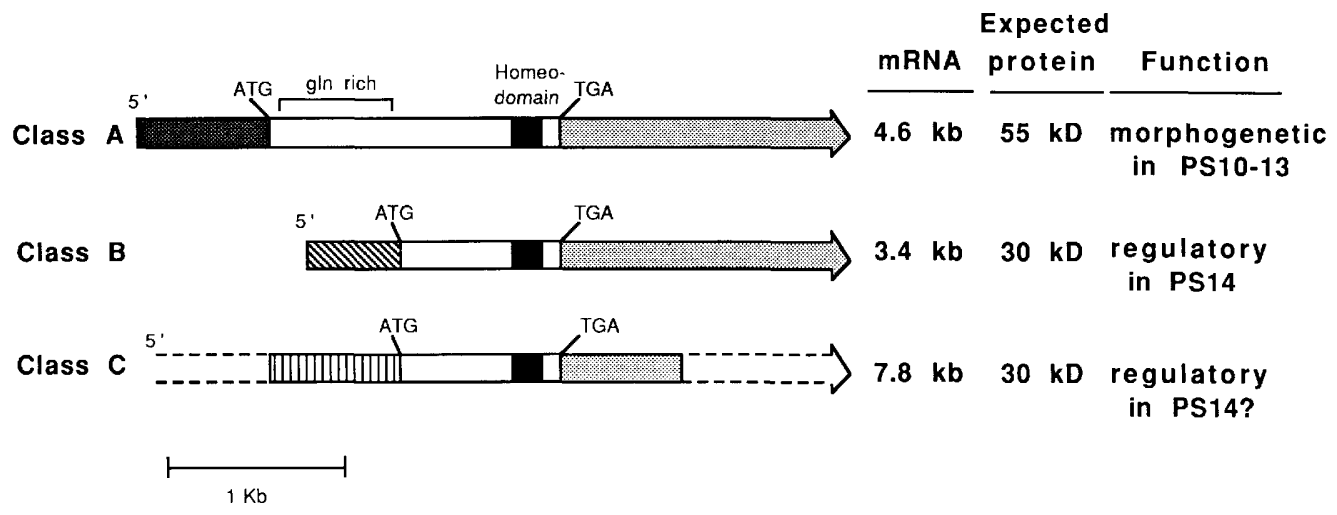

Figure 8. Summary of ORFs in the three classes of $A b d-B$ cDNAs. The sizes of mRNAs (in $\mathrm{kb}$ ) and predicted proteins ( $\mathrm{kD}$ ) and the assigned genetic function are indicated for each class of $A b d-B$ cDNA. The mRNA sizes are estimated from Northern analyses (Fig. 3 ) referred to in the text. The actual lengths of class A and B mRNAs (deduced from the sequence analysis of the cDNAs) are 4408 and 3039 nucleotides, respectively, excluding poly(A) tails. The cDNA structures are aligned at the $3^{\prime}$ end. The $5^{\prime}$-nontranslated regions are represented by different patterns to indicate that the $5^{\prime}$ end of each cDNA class is unique (see Figs. 6 and 7). Dashed lines denote the $5^{\prime}$ and $3^{\prime}$ regions of the $7.8-\mathrm{kb}$ mRNA that are missing from our class C cDNA.

If this is the case, it appears that the functional difference between the $m$ and $r$ proteins is a result of the presence or absence of the amino-terminal domain found in the longer $m$ protein (Fig. 8). This domain is almost totally devoid of charged amino acid residues, and it is associated with many stretches of Gln residues (the opa or $M$ repeat). Although repeats of Gln residues have been found in many Drosophila genes coding for regulatory proteins (Regulski et al. 1985; Wharton et al. 1985; Thisse et al. 1988), their functions remain obscure. A recent analysis of mammalian transcription factor SP1 in Drosophila tissue culture cells has indicated that glutamine-rich stretches function as activation domains (Courey and Tjian 1988). Therefore, it is possible that the glutamine-rich amino-terminal domain of the $m$ protein may provide activating functions that are absent from the truncated $r$ protein.

Other examples of genes with overlapping transcripts that encode two proteins that differ by the presence or absence of an amino-terminal domain have been reported. The full-length protein of the E2 ORF of bovine papillomavirus functions as a trans-activator, whereas a shorter protein composed of the carboxy-terminal domain serves as a repressor (Lambert et al. 1987). The recently described structure of a homeo box-containing gene from Xenopus, X1Hbox1, is strikingly similar to that of the $A b d-B$ gene (Cho et al. 1988). Overlapping transcripts are generated from two promoters that encode either a long or short protein containing the homeo box sequence.

The $m$ element of $A b d-B$ is required for proper development of PS10-PS13 (Casanova et al. 1986, 1987). Specification of the morphological characteristics of this region is thought to entail suppression of $U b x$ expression in posterior abdominal segments (Struhl and White 1985) and activation of the 'realizator' genes (Garcia-Bellido 1975), which are the cyto-differentiation genes responsible for the characteristics of these parasegments.
Although no downstream genes have yet been identified, it appears likely that the $m$ protein functions as a transcription activator, as has been shown for other homeo domain-containing proteins (Jaynes and O'Farrell 1988; Han et al. 1989; Krasnow et al. 1989; Winslow et al. 1989). In contrast, the primary function of the $r$ protein in the wild-type flies appears to be to repress other homeotic genes, including the Antennapedia P2 promoter (Boulet and Scott 1988) and the Abd-B m element (Casanova et al. 1986) that should not be expressed in PS14. The $r$ protein can also repress the expression of $a b d-A$ and $U b x$ in PS14 (Casanova et al. 1986; Casanova and White 1987). We suggest a model in which the unique amino-terminal domain of the $m$ protein is required for activation of other genes, whereas the $r$ protein lacking this domain can only act as a repressor. Because the carboxyl terminus, including the DNA-binding homeo domain (Desplan et al. 1988; Hoey and Levine 1988; Müller et al. 1988), is identical for the $m$ and $r$ proteins, both proteins may bind to the same DNA sequences. However, the binding of the $m$ or $r$ protein could lead to opposite consequences: transcriptional activation of the target genes by the $m$ protein, on one hand, and repression of the same genes by the $r$ protein on the other. The $m$ protein could also act as a repressor (e.g., $U b x$ expression) in the absence of factors needed to mediate activation. The proposed mechanism is similar to the wellcharacterized regulation of the $\lambda$ repressor $c I$ gene (Ptashne 1986), where binding of the cro protein to the operator represses transcription and binding by the larger repressor protein activates transcription.

A series of 'domain swap' or 'domain addition' experiments suggested that transcriptional regulatory proteins consist of a DNA-binding domain and an activator domain (for review, see Ptashne 1988). In the absence of the activator domain, the DNA-binding domain binds its target DNA sequence but fails to activate transcription. The structure of the $A b d-B$ gene suggests that a 
domain addition is used to produce two functionally different proteins from a single gene: one protein with an activator domain and one without it.

\section{Materials and methods}

cDNA screens and analysis of cDNAs

Two cDNA libraries were screened for cDNAs originating in the $A b d-B$ region. The $\lambda g t 10$ cDNA library constructed from $3-$ to 12-hr embryonic RNA (lot E6-8) by L. Kauver (Poole et al. 1985) was originally screened with a $0.6-\mathrm{kb}$ EcoRI fragment (kindly provided by S. Celniker) located at the genomic map coordinate +154 of the BX-C, using standard techniques (Maniatis et al. 1982) for handling phage $\lambda$ libraries. Positive clones from these screens were amplified and the cDNA inserts were transferred to pTZ vectors (U.S. Biochemicals). This library was subsequently rescreened with a $P v u I I-P s t I$ fragment specific for class A cDNA and a TaqI-NaeI fragment specific for class B cDNAs (Fig. 2). The cDNAs were initially mapped using restriction enzymes. Some clones were compared to each other for regions of homology by forming DNA duplexes between cDNA strands of opposite orientation in m13 phage DNA, digesting with S1 nuclease and determining the size of the resistant DNA fragments, as described by Bermingham and Scott (1988).

A cDNA plasmid library (Brown and Kafatos 1988) was screened with the class A-specific probe. Replica-plated colonies (Benton and Davis 1977) were lysed by a brief autoclaving and washed extensively in $0.1 \mathrm{M} \mathrm{NaH}_{2} \mathrm{PO}_{4}, 50 \mathrm{~mm}$ sodium pyrophosphate, $1 \mathrm{mM}$ EDTA, and $1 \%$ SDS. Probes were radiolabeled with the random primer method (Feinberg and Vogelstein 1983 and hybridized to the filters in $50 \%$ formamide, $5 \times$ SSPE, $0.1 \%$ SDS, $5 \times$ Denhardt's solution, $5 \%$ dextran sulfate, and 0.5 $\mathrm{mg} / \mathrm{ml}$ sheared, alkali-denatured, herring sperm DNA at $42^{\circ} \mathrm{C}$ for $12-18 \mathrm{hr}$. The filters were washed in $0.3 \times$ SSC, $0.1 \%$ SDS, at $68^{\circ} \mathrm{C}$. DNA inserts from positive clones detected in this screen were analyzed directly in the host vector pNB40.

\section{Southern hybridizations}

DNA fragments representing the entire cDNA insert were radiolabeled using the random primer method and hybridized to DNA restriction fragments spanning the entire $a b d-A$ and $A b d-B$ domains [genomic map position +25 to +205 of Karch et al. (1985)]. Phages 2255, 2265, 2279, 8004, 8019, 8035, 8053, $8060,8078,8083,8088$, and 8106 were cut with EcoRI, phage 2235 with SalI, and phages 8095 and 8099 with HindIII and EcoRI. The digested DNA fragments were fractionated on a $0.7 \%$ agarose gel and transferred to a nylon membrane (Nytran, Schleicher \& Schuell) using standard protocols (Maniatis et al. 1982). Hybridization conditions were the same as those used for the library screens.

\section{DNA sequencing}

Sequencing of DNA was performed with the dideoxy chain termination method of Sanger et al. (1977), using either the large fragment of DNA polymerase I (Pharmacia) or a modified T7 DNA polymerase (Sequenase, U.S. Biochemicals) following the manufacturer's reaction conditions. Both DNA strands were sequenced for class A cDNAs (nucleotides +1000 to +4408 for clone E32 and nucleotides +508 to +2170 for clone B3; Fig. 6), all unique regions of class $B$ (clone E19), and all regions of class $\mathrm{C}$ (clone E61) cDNAs. Only one strand of the common region (nucleotides +1870 to +4389 ; Fig. 6 ) of class B cDNA was sequenced to confirm its identity to class A cDNA. The genomic DNA upstream of class A cDNA clone B3 was sequenced on both strands for both wild-type DNA and the D14 mutant DNA. The $5^{\prime}$-flanking sequence upstream of class B cDNA clone E19 was also sequenced on both strands.

Subcloned DNA containing the deletion associated with a class I mutant, $i a b-7^{D 14}$, has been cloned and kindly provided by F. Karch. The deletion end points were approximated by restriction enzyme mapping and precisely localized by DNA sequencing using appropriate primers.

\section{RNA isolation}

Eggs were collected for $8 \mathrm{hr}$ from Canton-S strain flies maintained in population cages. Embryos were aged for $4 \mathrm{hr}$ at $25^{\circ} \mathrm{C}$, and RNA was isolated by homogenizing dechorionated embryos in $6 \mathrm{M}$ guanidine $\mathrm{HCl}, 0.1 \mathrm{M} \mathrm{Na}$ acetate $(\mathrm{pH} 5.2)$. After removing debris by centrifugation at $10,000 \mathrm{rpm}$ in an SS 34 rotor for $10 \mathrm{~min}$, the RNA was pelleted through a cushion of 5.7 $\mathrm{M} \mathrm{CsCl}$ in an SW 41 rotor at $37,000 \mathrm{rpm}$ for $18 \mathrm{hr}$. The RNA pellet was resuspended in TE $[10 \mathrm{~mm}$ Tris $-\mathrm{HCl}(\mathrm{pH} 7.8), 1 \mathrm{~mm}$ EDTA], and precipitated with ethanol before poly $(\mathrm{A})^{+}$selection. Poly $(\mathrm{A})^{+}$RNA was isolated by a single passage of total RNA through an oligo(dT)-cellulose column (Collaborative Research) and then concentrated by ethanol precipitation before further use.

\section{Northern analysis}

Ten micrograms of poly $(\mathrm{A})+$ RNA was fractionated on a $1.2 \%$ agarose formaldehyde gel, as described in Maniatis et al. (1982). The gel was alkali-treated and neutralized, and the RNA was transferred to a Duralon uncharged nylon membrane (Stratagene) for $16 \mathrm{hr}$ with $20 \times$ SSPE. The RNA was fixed to the membrane with UV light (120 mJ in a Stratagene Stratalinker). Hybridization and wash conditions were those of Sánchez-Herrero and Crosby (1988). Single-stranded probes were made by hybridization of 1 pmole of the M13 'universal primer' to $\sim 100$ ng of single-stranded DNA derived from pTZ vectors containing the appropriate cDNA subclone. The primer was extended with the large fragment of DNA polymerase $I$ in the presence of $1 \mu \mathrm{M}\left[\alpha^{-32} \mathrm{P}\right] \mathrm{dATP}$ (Amersham, $3000 \mathrm{Ci} / \mathrm{mmole}$ ) and $180 \mu \mathrm{M}$ each of dCTP, dGTP, and dTTP for $10 \mathrm{~min}$. Extension was continued in the presence of $25 \mu \mathrm{M}$ unlabeled dATP for 10 min, and the DNA was digested with a restriction enzyme distal to the priming site for synthesis. The DNA was denatured with dimethylsulfoxide (DMSO) and heat, and fractionated on $1.4 \%$ low-gelling-temperature agarose (FMC Bioproducts). A gel slice containing the single-stranded probe was melted and diluted with hybridization buffer. Approximately $32,000-160,000 \mathrm{cpm} / \mathrm{cm}^{2}$ of filter was used for each hybridization. An RNA size standard ranging from 9.5 to $0.3 \mathrm{~kb}$ (BRL) was run in adjacent lanes for use in estimating RNA sizes. It was visualized by hybridization to radioactive, random primerlabeled $\lambda$-phage DNA.

\section{S1 analysis}

For analysis of the $5^{\prime}$ of the 4.6-kb RNA, uniformly radiolabeled, single-stranded probes were synthesized as described for Northern analysis. A primer complementary to nucleotides +162 to +191 (Fig. 6) was used to prime DNA synthesis on a PstI-BamHI genomic subclone (Fig. $4 \mathrm{C}$; nucleotides +443 to -345 in Fig. 6). The DNA was cut at the BamHI site, and a 536-base single-stranded probe was isolated on a low-gellingtemperature agarose gel.

For analysis of the 5' end of 3.4-kb RNA, a primer (nucleotides +275 to +294 in Fig. 7) was hybridized to an EcoRI-HindIII fragment from the genomic position +182 to +186 and extended with the large fragment of DNA polymerase I in the 
presence of a radioactive nucleotide, as described above. The extended DNA was digested with PstI, resulting in a 940-base probe that was isolated on a low-gelling-temperature agarose gel.

The radioactively labeled probe was hybridized to $1 \mu \mathrm{g}$ of 4 to 12 -hr Drosophila poly(A) ${ }^{+}$RNA, $10 \mu \mathrm{g}$ of 4- to 12 -hr Drosophila total RNA, or $1 \mu \mathrm{g}$ of yeast poly $(\mathrm{A})^{+}$RNA at an RNA concentration of $\sim 1 \mathrm{mg} / \mathrm{ml}$ in $50 \mathrm{mM}$ PIPES (pH 6.4), $5 \times$ SSC, and $1 \mathrm{mM}$ EDTA by heating to $85^{\circ} \mathrm{C}$ for $5 \mathrm{~min}$ and then incubating at $50^{\circ} \mathrm{C}$ for $3 \mathrm{hr}$. The hybridization mixes were cooled on ice and diluted 10- to 25 -fold in $30 \mathrm{mM} \mathrm{Na}$ acetate (pH 4.5), 0.25 $\mathrm{M} \mathrm{NaCl}, 1 \mathrm{mM} \mathrm{ZnSO}_{4}$, and 5\% glycerol. The DNA-RNA hybrids were then digested with 60 units of S1 nuclease (U.S. Biochemicals) at $15^{\circ} \mathrm{C}$ for $1 \mathrm{hr}$. The protected fragments were precipitated and electrophoresed on $6 \%$ acrylamide $/ 7 \mathrm{M}$ urea gels.

\section{Primer extensions}

The primers used in primer extension analysis were prepared as follows. For analysis of the 4.6-kb RNA, an oligonucleotide complementary to +125 to +151 in Figure $6\left(5^{\prime}\right.$-GTGAATGGACGGCGAGTACGAAATCGT-3') was hybridized with the PstI-BamHI genomic subclone (nucleotides +443 to -345 in Fig. 6) from map position +158 and extended with the large fragment of DNA polymerase $I$ in the presence of both $\left[\alpha^{-32} \mathrm{P}\right] \mathrm{dCTP}$ and $\left[\alpha^{-32} \mathrm{P} \mid \mathrm{dATP}\right.$, as described above for the production of single-stranded probes for Northern analysis. The extended DNA was digested with BssHII (nucleotide +39 in Fig. 6). This results in a uniformly radiolabeled fragment of $113 \mathrm{nu}-$ cleotides. For analysis of the $3.4-\mathrm{kb}$ RNA, a radioactively labeled, 253-nucleotide-long primer was synthesized similarly by first hybridizing an oligonucleotide complementary to nucleotides +275 to +294 of Figure 5 (5'-GAGTTTATATGACATATATG-3') to an EcoRI-HindIII subclone from the genomic position +182 to +186 , extending with the large fragment of DNA polymerase I and digesting with BssHII (nucleotide +42 of Fig. 7). The radioactively labeled probes were separated on $8 \%$ acrylamide $/ 7 \mathrm{~m}$ urea gels, eluted overnight from crushed gel slices in distilled water, and concentrated by ethanol precipitation.

Approximately $1.5-9 \mathrm{ng}(50,000-300,000 \mathrm{cpm})$ was hybridized to RNA as described above for the $S 1$ analysis, except that hybridization was done at $70^{\circ} \mathrm{C}$ for $3 \mathrm{hr}$ for the 113 - and 253 base probes. The hybridized primers were extended in a reaction mixture of $50 \mathrm{mM}$ Tris- $\mathrm{HCl}(\mathrm{pH} 8.0), 50 \mathrm{mM} \mathrm{KCl}, 10 \mathrm{~mm}$ $\mathrm{MgCl}_{2}, 1 \mathrm{mM} \mathrm{DTT}$, 40 units RNasin (Promega), and $0.5 \mathrm{~mm}$ each dATP, dTTP, dCTP, and dGTP, using 3 units of reverse transcriptase (Seikagaku) for $30 \mathrm{~min}$ at $42^{\circ} \mathrm{C}$. Subsequently, the reaction was treated with RNase A $(250 \mu \mathrm{g} / \mathrm{ml}$, Worthington) for $15 \mathrm{~min}$ at $37^{\circ} \mathrm{C}$ and extracted with phenol/chloroform $(1: 1)$. The extension products were concentrated by ethanol precipitation and electrophoresed on $6 \%$ acrylamide $/ 7 \mathrm{M}$ urea gels.

\section{Acknowledgments}

We thank Larry Kauvar, Tom Kornberg, and Nick Brown for the cDNA libraries, François Karch for the D14 subclone, Sue Celniker for a genomic DNA subclone, and Ernesto Sánchez-Herrero, Lynn Crosby, and Bill McGinnis for valuable discussions. Robin Acres provided excellent technical assistance. We are especially grateful for the critical reading of this manuscript by Bruce Appel, Anne Boulet, Susan Cumberledge, Tulle Hazelrigg, Michele Lamka, and Carl Thummel.

\section{Note added in proof}

Sequence data described in this paper have been submitted to the EMBL/GenBank Data Libraries.

\section{References}

Akam, M.E. 1983. The location of Ultrabithorax transcripts in Drosophila tissue sections. EMBO I. 2: 2075-2084.

- 1987. The molecular basis for metameric pattern in the Drosophila embryo. Development 101: 1-22.

Akam, M.E. and A. Martinez-Arias. 1985. The distribution of Ultrabithorax transcripts in Drosophila embryos. EMBO I. 4: $1689-1700$.

Beachy, P.A., S.L. Helfand, and D.S. Hogness. 1985. Segmental distribution of bithorax complex proteins during Drosophila development. Nature 313: 545-551.

Bender, W., M. Akam, F. Karch, P.A. Beachy, M. Peifer, P. Spierer, E.B. Lewis, and D.S. Hogness. 1983. Molecular genetics of the bithorax complex in Drosophila melanogaster. Science 221: 23-29.

Benton, W.D. and R.W. Davis. 1977. Screening $\lambda$ gt recombinant clones by hybridization to single plaques in situ. Science 196: $180-182$.

Bermingham, J.R., Jr. and M.P. Scott. Developmentally regulated alternative splicing of transcripts from the Drosophila homeotic gene Antennapedia can produce four different proteins. EMBO I. 7: 3211-3222.

Benyajati, C., N. Spoerel, H. Haymerle, and M. Ashburner. 1983. The messenger RNA for alcohol dehydrogenase in Drosophila melanogaster differs in its $5^{\prime}$ end in different developmental stages. Cell 33: 125-133.

Bhandari, B., K.D. Beckwith, and R.E. Miller. 1988. Cloning, nucleotide sequence, and potential regulatory elements of the glutamine synthetase gene from murine 3T3-L1 adipocytes. Proc. Natl. Acad. Sci. 85: 5789-5793.

Bossy, B., M. Ballivet, and P. Spierer. 1988. Conservation of neural nicotinic acetylcholine receptors from Drosophila to vertebrate central nervous system. EMBO J. 7: 611-618.

Boulet, A.M. and M.P. Scott. 1988. Control elements of the P2 promoter of the Antennapedia gene. Genes Dev. 2: 16001614.

Brown, N.M. and F.C. Kafatos. 1988. Functional cDNA libraries from Drosophila embryos. I. Mol. Biol. 203: 425-437.

Casanova, J. and R.A.H. White. 1987. Trans-regulatory functions in the Abdominal-B gene of the bithorax complex. Development 101: 117-122.

Casanova, J., E. Sánchez-Herrero, and G. Morata. 1986. Identification and characterization of a parasegment specific regulatory element of the Abdominal-B gene of Drosophila. Cell 47: 627-636.

Casanova, J., E. Sánchez-Herrero, A. Busturia, and G. Morata. 1987. Double and triple mutant combination of the bithorax complex of Drosophila. EMBO J. 6: 3103-3109.

Celniker, S.E. and E.B. Lewis. 1987. Transabdominal, a dominant mutant of the bithorax complex, produces a sexually dimorphic segmental transformation in Drosophila. Genes Dev. 1: 111-123.

Cho, K.W.Y., J. Goetz, C.V.E. Wright, A. Fritz, J. Hardwicke, and E.M. DeRobertis. 1988. Differential utilization of the same reading frame in a Xenopus homeobox gene encodes two related proteins sharing the same DNA-binding specificity. $E M B O$ /. 7: 2139-2149.

Courey, A.J. and R. Tjian. 1988. Analysis of Spl in vivo reveals multiple transcriptional domains, including a novel glutamine-rich activation motif. Cell 55: 887-898.

DeLorenzi, M., N. Ali, G. Saari, C. Henry, M. Wilcox, and M. Bienz. 1988. Evidence that the Abdominal-B element function is conferred by a trans-regulatory homeoprotein. $E M B O$ J. 7: 3223-3231.

Desplan, C., J. Theis, and P.H. O'Farrell. 1988. The sequence specificity of homeodomain-DNA interaction. Cell 
54: $1081-1090$.

Duncan, I. 1987. The bithorax complex. Annu. Rev. Genet. 21: $285-319$.

Feinberg, A. and B. Vogelstein. 1983. A technique for radiolabeling DNA restriction endonuclease fragments to high specific activity. Anal. Biochem. 132: 6-13.

Garcia-Bellido, A. 1975. Genetic control of wing development in Drosophila. Cell Patterning. Ciba Found. Symp. 29: $161-182$.

Han, K., M.S. Levine, and J.L. Manley. 1989. Synergistic activation and repression of transcription by Drosophila homeobox proteins. Cell 56: 573-583.

Hoey, T. and M. Levine. 1988. Divergent homeo box proteins recognize similar DNA sequences in Drosophila. Nature 332: $858-861$.

Jaynes, J.B. and P.H. O'Farrell. 1988. Activation and repression of transcription by homeodomain-containing proteins that bind a common site. Nature 336: 744-749.

Karch, F., B. Weiffenbach, M. Peifer, W. Bender, I. Duncan, S. Celniker, M. Crosby, and E.B. Lewis. 1985. The abdominal region of the bithorax complex. Cell 43: 81-96.

Kornfeld, L., R.B. Saint, P.A. Beachy, P.J. Harte, D.A. Peattie, and D.S. Hogness. 1989. Structure and expression of a family of Ultrabithorax mRNAs generated by alternative splicing and polyadenylation in Drosophila. Genes Dev. 3: 243-258.

Krasnow, M.A., E.E. Saffman, K. Kornfeld, and D.S. Hogness. 1989. Transcriptional activation and repression by Ultrabithorax proteins in cultured Drosophila cells. Cell 57: 1031-1043.

Kuziora, M.A. and W. McGinnis. 1988. Different transcripts of the Drosophila $A b d-B$ gene correlate with distinct genetic sub-functions. EMBO I. 7: 3233-3244.

Lambert, P.F., B.A. Spalholz, and P.M. Howley. 1987. A transcriptional repressor encoded by BPV-1 shares a common carboxy-terminal domain with the E2 transactivator. Cell 50: $69-78$.

Laughon, A., A.M. Boulet, J.R. Bermingham, R.A. Laymon, and M.P. Scott. 1986. The structure of transcripts from the homeotic Antennapedia gene of Drosophila: Two promoters control the major protein-coding region. Mol. Cell. Biol. 6: 4676-4689.

Lewis, E.B. 1978. A gene complex controlling segmentation in Drosophila. Nature 276: 565-570.

- 1985. Regulation of the genes of the bithorax complex in Drosophila. Cold Spring Harbor Symp. Quant. Biol. 50: $155-164$.

Maniatis, R., E.F. Fritsch, and J. Sambrook. 1982. Molecular cloning: A laboratory manual. Cold Spring Harbor Laboratory, Cold Spring Harbor, New York.

Mlodzik, M. and W.J. Gehring. 1987. Expression of the caudal gene in the germ line of Drosophila: Formation of an RNA and a protein gradient during early embryogenesis. Cell 48: $465-478$.

Müller, M., M. Affolter, W. Leupin, G. Otting, K. Würthrich, and W.J. Gehring. 1988. Isolation and sequence-specific DNA binding of the Antennapedia homeodomain. EMBO $J$. 7: 4299-4304.

O'Connor, M.B., R. Binari, L. Perkins, and W. Bender. 1988. Alternative RNA products from the Ultrabithorax domain of the bithorax complex. EMBO J. 7: 435-445.

Peabody, D.S. 1989. Translation initiation at non-AUG triplets in mammalian cells. J. Biol. Chem. 264: 5031-5035.

Peifer, M., F. Karch, and W. Bender. 1987. The bithorax complex: control of segmental identity. Genes Dev. 1: 891-898.

Pirrotta, V., E. Manet, E. Hardon, S.E. Bickel, and M. Benson. 1987. Structure and sequence of the Drosophila zest gene. EMBO I. 6: 791-799.

Poole, S.J., L.M. Kauzar, B. Drees, and T. Kornberg. 1985. The engrailed locus of Drosophila: Structural analysis of an em- bryonic transcript. Cell 40: 37-43.

Ptashne, M. 1987. A genetic switch. Cell Press, Cambridge, Massachussetts and Blackwell Scientific Publications, Palo Alto, California.

- 1988. How eukaryotic transcriptional activators work. Nature 335: 683-689.

Regulski, M., K. Harding, R. Kostriken, F. Karch, M. Levine, and W. McGinnis. 1985. Homeo box genes of the antennapedia and bithorax complexes of Drosophila. Cell 43: 7180.

Sánchez-Herrero, E. and M.A. Crosby. 1988. The Abdominal-B gene of Drosophila melanogaster: Overlapping transcripts exhibit two different spatial distributions. EMBO $J$. 7: 2163-2173.

Sánchez-Herrero, E., J. Casanova, S. Kerridge, and G. Morata. 1985a. Anatomy and function of the bithorax complex of Drosophila. Cold Spring Harbor Symp. Quant. Biol. 50: $165-172$.

Sánchez-Herrero, E., I. Vernós, R. Marco, and G. Morata. 1985b. Genetic organization of Drosophila bithorax complex. $\mathrm{Na}$ ture 313: 108-113.

Sanger, F., S. Nicklen, and A.R. Coulson. 1977. DNA sequencing with chain-terminating inhibitors. Proc. Natl. Acad. Sci. 74: 5463-5467.

Sato, T. and R.E. Denell. 1986. Segmental identity of caudal cuticular features of Drosophila melanogaster larvae and its control by the bithorax complex. Dev. Biol. 116: 78-91.

Schibler, U. and F. Sierra. 1987. Alternative promoters in developmental gene expression. Annu. Rev. Genet. 21: 237-257.

Schneuwly, S., A. Kuroiwa, P. Baumgartner, and W.J. Gehring. 1986. Structural organization and sequence of the homeotic gene Antennapedia of Drosophila melanogaster. EMBO J. 5: 733-739.

Stroeher, V.L., E.M. Jorgensen, and R.L. Garber. 1986. Multiple transcripts from the Antennapedia gene of Drosophila. Mol. Cell. Biol. 6: $4667-4675$.

Struhl, G. and R.A.H. White. 1985. Regulation of the Ultrabithorax gene of Drosophila by other bithorax complex genes. Cell 43: 507-519.

Thisse, B., C. Stoetzel, C. Gorostiza-Thisse, and F. PerrinSchmitt. 1988. Sequence of the twist gene and nuclear localization of its protein in endomesodermal cells of early Drosophila embryos. EMBO J. 7: 2175-2183.

Tiong, S.Y.K., L.M. Bone, and J.R.S. Whittle. 1985. Recessive lethal mutations within the bithorax complex in Drosophila. Mol. Gen. Genet. 200: 335-342.

Tiong, S.Y.K., M.C. Gribbin, and J.R.S. Whittle. 1988. Mutational dissection of gene expression in the abdominal region of the bithorax complex of Drosophila in imaginal tissue. Wilhelm Roux's Arch. Dev. Biol. 197: 131-140.

Weinzierl, R., J.M. Axton, A. Ghysen, and M. Akam. 1987. UItrabithorax mutations in constant and variable regions of the protein coding sequence. Genes Dev. 1: 386-397.

Wharton, K.A., B. Yedvobnick, V.G. Finnerty, and S. ArtavanisTsakonas. 1985. opa: A novel family of transcribed repeats shared by the notch locus and other developmentally regulated loci in D. melanogaster. Cell 40: 55-62.

White, R.A.H. and M. Wilcox. 1984. Protein products of the bithorax complex in Drosophila. Cell 39: 163-171.

- 1985. Regulation of the distribution of Ultrabithorax proteins in Drosophila. Nature 318: 563-567.

Whittle, J.R.S., S.Y.K. Tiong, and C.E. Sunkel. 1986. The effect of lethal mutations and deletions within the bithorax complex upon the identity of caudal metameres in the Drosophila embryo. I. Embryol. Exp. Morph. 93: 153-166.

Winslow, G.M., S. Hayashi, M. Krasnow, D.S. Hogness, and M.P. Scott. 1989. Transcriptional activation by the Antennapedia and fushi tarazu proteins in cultured Drosophila cells. Cell 57: 1017-1030.

GENES \& DEVELOPMENT

1981 


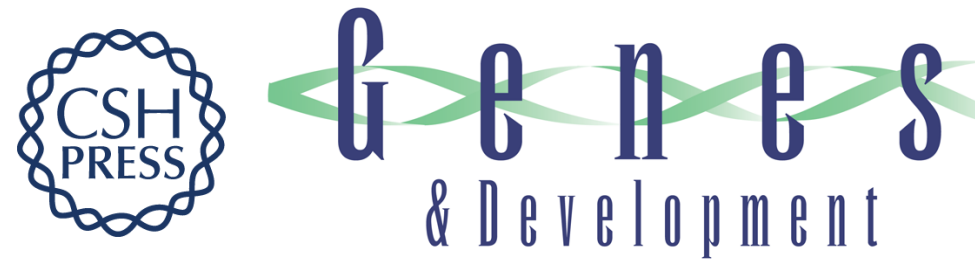

\section{The morphogenetic and regulatory functions of the Drosophila Abdominal-B gene are encoded in overlapping RNAs transcribed from separate promoters.}

M Zavortink and S Sakonju

Genes Dev. 1989, 3:

Access the most recent version at doi:10.1101/gad.3.12a.1969

References This article cites 60 articles, 15 of which can be accessed free at:

http://genesdev.cshlp.org/content/3/12a/1969.full.html\#ref-list-1

License

Email Alerting Service

Receive free email alerts when new articles cite this article - sign up in the box at the top right corner of the article or click here.

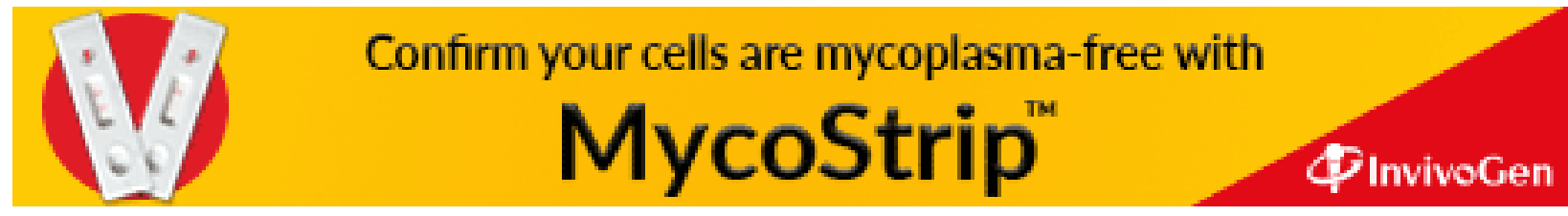

